\title{
Anatomical association of fluid yielding ducts with location of the breast cancer affected segment in screen detected and symptomatic breast cancer GPH Gui*1, D Twelves ${ }^{1,3}$, A Nerurkar ${ }^{2}$, P Osin $^{2}$, A Ward ${ }^{1}$ and CM Isacke ${ }^{3}$
}

\author{
Address: ${ }^{1}$ Academic Surgery (Breast Unit), Institute of Cancer Research, London, UK, ${ }^{2}$ Department of Histopathology, Royal Marsden NHS Trust, \\ Institute of Cancer Research, London, UK and ${ }^{3}$ Breakthrough Breast Cancer, Institute of Cancer Research, London, UK \\ Email: GPH Gui* - gerald.gui@rmh.nhs.uk \\ * Corresponding author
}

from 6th International Symposium on the Intraductal Approach to Breast Cancer Santa Monica, CA, USA. 19-2I February 2009

Published: 24 July 2009

BMC Proceedings 2009, 3(Suppl 5):SI3 doi:10.1186/1753-656I-3-S5-SI3

This abstract is available from: http://www.biomedcentral.com/I753-656I/3/S5/SI3

(C) 2009 Gui et al; licensee BioMed Central Ltd.

\section{Introduction}

The concept of the intraductal approach to evaluating the breast microenvironment assumes direct access to the breast cancer containing duct. Previous studies on duct anatomy infusing a dye or contrast found fluid-yielding ducts to be associated with the cancer containing duct in approximately $50 \%$ of fluid-yielding breasts with cancer. A concordant anatomical relationship between accessible ductal sytems and the cancer-affected lobe is essential if cytology or other cell markers are to be successfully identified as indicators of cancer or of early cancerous change. The concordant relationship is less important if field change effects are considered to predictors of malignant change. The aim of this study was to determine how often duct lavage effluent drains the breast cancer affected segment.

\section{Methods}

40 patients undergoing therapeutic mastectomy for breast cancer were studied (31 symptomatic and 9 screendetected). Following successful ductal lavage, the mastectomy specimens were infused ex-vivo with coloured polyurethane elastomer resin (VasQtec, Zurich). The extent of specimen infusion with resin and the direct anatomical relationship to the cancer affected segment were recorded.

\section{Results}

The median number of successful ducts cannulated per cancer affected breast was 2 (range 1-3). 23/40 (58\%) therapeutic mastectomy specimens showed successful tracing of the cancer-affected duct system. 5/38 (13\%) resin infusions traced duct systems unaffected by cancer and the remaining 12/40 (30\%) infusions extravasated. Of the 23 successful tracings, 16 mastectomy specimens contained symptomatic cancer and the remaining 7 were screen-detected nonpalpable cancers. All 12 extravasated infusions occurred in specimens with symptomatic cancer. 7/23 successful infusions showed abnormal cytology concordant with the cancer affected segment.

\section{Conclusion}

Breast duct systems of both symptomatic and non-palpable cancer were equally accessed at successful ductal lavage. The duct system of the cancer affected segment was concordant to a fluid yielding duct patent in 58 percent of cases, a similar finding to previous studies. Mastectomy specimens containing clinically impalpable disease were more likely to remain patent than those with palpable lesions, implying distal duct collapse following duct obstruction by larger tumours impedes access to the cancer affected lobe. Future studies that depend on direct access to the cancer affected segment (eg cytology) are likely to be limited by duct accessibility while studies that 
demonstrate field change effects (eg protein studies) are less dependent on duct patency.

Publish with Biomed Central and every scientist can read your work free of charge

"BioMed Central will be the most significant development for disseminating the results of biomedical research in our lifetime. " Sir Paul Nurse, Cancer Research UK

Your research papers will be:

- available free of charge to the entire biomedical community

- peer reviewed and published immediately upon acceptance

- cited in PubMed and archived on PubMed Central

- yours - you keep the copyright 